\title{
The El Niño - La Niña cycle and recent trends in supply and demand of net primary productivity in African drylands
}

\author{
A. M. Abdi $^{1} \cdot$ A. Vrieling $^{2}$ - G. T. Yengoh ${ }^{3}$. \\ A. Anyamba ${ }^{4}$. J. W. Seaquist ${ }^{1}$ - C. C. Ummenhofer ${ }^{5}$. \\ J. Ardö ${ }^{1}$
}

\begin{abstract}
Inter-annual climatic variability over a large portion of sub-Saharan Africa is under the influence of the El Niño-Southern Oscillation (ENSO). Extreme variability in climate is a threat to rural livelihoods in sub-Saharan Africa, yet the role of ENSO in the balance between supply and demand of net primary productivity (NPP) over this region is unclear. Here, we analyze the impact of ENSO on this balance in a spatially explicit framework using gridded population data from the WorldPop project, satellite-derived data on NPP supply, and statistical data from the United Nations. Our analyses demonstrate that between 2000 and 2013 fluctuations in the supply of NPP associated with moderate ENSO events average $\pm 2.8 \mathrm{~g} \mathrm{C} \mathrm{m}^{-2} \mathrm{yr}^{-1}$ across sub-Saharan drylands. The greatest sensitivity is in arid Southern Africa where a $+1{ }^{\circ} \mathrm{C}$ change in the Niño-3.4 sea surface temperature index is associated with a mean change in NPP supply of $-6.6 \mathrm{~g} \mathrm{C} \mathrm{m}^{-2} \mathrm{yr}^{-1}$. Concurrently, the population-driven trend in NPP demand averages $3.5 \mathrm{~g} \mathrm{C} \mathrm{m}^{-2} \mathrm{yr}^{-1}$ over the entire region with densely populated urban areas exhibiting the highest mean demand for NPP. Our findings highlight the importance of accounting for the role ENSO
\end{abstract}

A. M. Abdi

hakim.abdi@gmail.com

1 Department of Physical Geography and Ecosystem Science, Lund University, Sölvegatan 12 , 22362 Lund, Sweden

2 Faculty of Geo-information Science and Earth Observation, University of Twente, P.O. Box 217, 7500 AE Enschede, The Netherlands

3 Lund University Center for Sustainability Studies, 22362 Lund, Sweden

4 Goddard Space Flight Center, Biospheric Sciences Laboratory, National Aeronautics and Space Administration, Greenbelt, MD, USA

5 Department of Physical Oceanography, Woods Hole Oceanographic Institution, Woods Hole, MA, USA 
plays in modulating the balance between supply and demand of NPP in sub-Saharan drylands. An important implication of these findings is that increase in NPP demand for socio-economic metabolism must be taken into account within the context of climate-modulated supply.

Keywords Sub-Saharan Africa $\cdot$ Drylands $\cdot$ El Niño-southern oscillation · Net primary productivity $\cdot$ Climate variability

\section{Introduction}

Drylands cover more than half of sub-Saharan Africa and are characterized by a combination of low rainfall and high potential evapotranspiration that leads to low levels of soil moisture and net primary productivity (NPP) (Nicholson 2011). In these regions, climatic variability is one of the most acute and widespread threats to the agro-pastoral systems that are inhabited by $60 \%$ of the population (IPCC 2014). Most of sub-Saharan Africa has one rainy season (East Africa has two) that is modulated by large-scale ocean-atmosphere teleconnections. The largest of these, the El Niño-Southern Oscillation (ENSO), has been identified as a dominant factor that regulates inter-annual photosynthetic activity in global drylands (Ahlström et al. 2015). The two extreme phases of ENSO, El Niño and La Niña, represent positive and negative departures, respectively, from long term mean sea surface temperatures in the central and eastern equatorial Pacific Ocean. El Niño generally brings dry conditions to parts of the Sahel and most of Southern Africa, and wet conditions to Eastern Africa, while La Niña is associated with approximately opposite conditions (Giannini et al. 2008). These dry or wet conditions are exacerbated in severe El Niño or La Niña events, causing droughts or floods that reduce the amount of NPP in a given area. The most recent example of the impact of a severe El Niño is the 2015/16 drought in Southern Africa, where the October 2015 - March 2016 rainfall was $75 \%$ below the 1982-2011 average (FEWSNET 2016). The 2011/12 famine in the Horn of Africa exemplifies a confluence of risk factors, such as political instability, armed conflict and inaccessibility, exacerbated by La Niña. The strong La Niña of 2010/11 (Supplementary Fig. 2) induced the failure of both the short rains in late 2010 and the long rains in mid-2011, causing collapses in both agricultural production and the associated labor market in Somalia (Maxwell and Fitzpatrick 2012).

NPP supplies the annual provision of crops, animal feed and pasture, and adds to annual increments of woody biomass (Running 2012). The societal implications of reduced NPP can be severe and could lead to crop failure and eventual food insecurity (Battisti and Naylor 2009). Sub-Saharan Africa has experienced a steep increase in demand for NPP in the twentieth century, which is likely to continue rising as a function of population growth and per capita consumption (Fetzel et al. 2016). Furthermore, recent studies predict an $11.7 \%$ decrease in the productivity of major sub-Saharan crops (wheat, maize, sorghum and millet) by the 2050s (Knox et al. 2012), expansion of drylands, particularly in the Sahel, East and Southern Africa (Greve et al. 2014), and an increased frequency of severe ENSO events (Cai et al. 2015). Thus, the effects of extreme climatic variability could have drastic impacts on NPP supply and intensified by the need to keep pace with an increasing population (Campbell et al. 2014).

Here, we adopt the concepts of "supply" and "demand" to demonstrate the linkage between ecosystem productivity, human livelihood, and inter-annual climatic variability in sub-Saharan drylands. As demand for food, feed and fuel drives land use change, the proportion of NPP 
required by humans relative to its supply (demand-supply ratio, DSR) could serve as an integrative benchmark of human dependence on ecosystems. We focus on ENSO and investigate its role in the balance between supply and demand of NPP in sub-Saharan drylands using a spatially explicit framework. We focus on the time period between 2000 and 2013 for NPP supply and 2000-2011 for NPP demand and DSR. The shorter time period for NPP demand and DSR is due to the fact that data on domestic supply quantities for several items, such as crops and woodfuel, were limited to 2011 at the time of writing. Our specific aims are to (1) quantify trends in NPP supply and demand in sub-Saharan drylands for 2000-2011; (2) map the spatial variability of NPP and DSR anomalies during ENSO years for 2000-2011; (3) assess the relationship between ENSO and NPP supply for 2000-2013.

\section{Data and methods}

\subsection{Derivation of NPP supply}

The estimation of NPP supply was performed using the light use efficiency approach as defined in Monteith (1972) and applied in the MOD17 algorithm of the moderate-resolution imaging spectroradiometer (MODIS) sensor on board the Terra and Aqua satellites:

$$
N P P_{\text {Supply }}=\left(P A R^{*} \mathrm{FPAR}^{*} \varepsilon_{\max } * V P D^{*} T_{\min }\right)-R a
$$

where $\mathrm{NPP}_{\text {Supply }}$ is the NPP available in the ecosystem regardless of land use type in grams of carbon per meter square per year $\left(\mathrm{g} \mathrm{C} \mathrm{m}^{-2} \mathrm{yr}^{-1}\right)$; PAR is incoming photosynthetically active radiation in megajoules per meter square per year $\left(\mathrm{MJ} \mathrm{m}^{-2} \mathrm{yr}^{-1}\right)$; FPAR is the fraction of incident PAR absorbed by the vegetation canopy; $\varepsilon_{\max }$ represents maximum light use efficiency, in grams of carbon per megajoule of PAR $\left(\mathrm{g} \mathrm{C} \mathrm{MJ}^{-1}\right)$, under hypothetical biome-specific ideal conditions; VPD and $T_{\min }$ are simple linear ramp functions of vapor pressure deficit and minimum temperature, respectively, which constrain maximum light use efficiency; Ra (autotrophic respiration) represents the amount of carbon respired, in $\mathrm{g} \mathrm{C} \mathrm{m}^{-2} \mathrm{yr}^{-1}$, during maintenance and growth respiration of leaves, fine roots and woody tissue. Further descriptions of the MOD17 algorithm are detailed in Zhao et al. (2011) and the dataset is available from the NASA Earth Observation System repository at the University of Montana (http://www.ntsg.umt.edu/project/mod17). NPP supply estimates were restricted to sub-Saharan Africa's arid, semi-arid and dry sub-humid areas (Supplementary Fig. 1).

\subsection{Niño-3.4 index and standardized anomalies}

We used the Niño-3.4 sea surface temperature index as a representation of ENSO. To differentiate between positive, negative and neutral ENSO years, we applied the threshold set by the National Oceanic and Atmospheric Administration. Accordingly, an ENSO year is characterized by a minimum of five consecutive 3-month running mean of the Extended Reconstructed Sea Surface Temperature version 3b (ERSST.v3b) anomalies in the Niño 3.4 region based on a threshold of $\pm 0.5^{\circ} \mathrm{C}$ (Supplementary Fig. 2). The base period for computing the anomalies in ERSST.v3b is 1971-2000. To visualize differences in NPP between the three ENSO phases (El Niño, La Niña, Neutral), standardized anomalies (Z-scores) were calculated for 
NPP supply and DSR using Eqs. 2-4. The ENSO cycle begins around July, peaks in December February (of the following year), starts to decay in March - April, and enters the post-phase in May - June (Philippon et al. 2014). The monthly NPP supply anomalies reflect this July to June cycle and were summed to annual values spanning two calendar years (1999/00, 2000/01, 2001/02, etc.). However, the data used to compute NPP demand are provided in single calendar years $(2000,2001,2002$, etc.). Therefore, DSR anomalies correspond to the years in the second half of the ENSO cycle to account for the lagged effect of the peak and decay phases of ENSO.

$$
\begin{aligned}
& Z_{E l \_ \text {Ni o }}=\sum_{t=1999 / 00}^{2010 / 11} \frac{O B S_{N P P, t}-M N_{N P P, t}}{S D_{N P P, t}} \text {, if } \mathrm{Nino}_{2} .4_{t} \geq+0.5 \\
& Z_{L a \_ \text {Nia }}=\sum_{t=1999 / 00}^{2010 / 11} \frac{O B S_{N P P, t}-M N_{N P P, t}}{S D_{N P P, t}} \text {, if } \quad \text { Nino3.4 }{ }_{t} \leq-0.5 \\
& Z_{\text {Neutral }}=\sum_{t=1999 / 00}^{2010 / 11} \frac{O B S_{N P P, t}-M N_{N P P, t}}{S D_{N P P, t}} \text {, if } \quad-0.5<\text { Nino3 }_{2} 4_{t}<+0.5
\end{aligned}
$$

where, $\mathrm{OBS}_{N P P, t}, \mathrm{MN}_{N P P, t}, \mathrm{SD}_{N P P, t}$ are the observed, mean, and standard deviation, respectively, of NPP supply, demand or DSR at time $t$.

\subsection{Derivation of NPP demand}

We define the term "consumption" as the actual amount of NPP extracted from the ecosystem as reported in the statistical database of the Food and Agriculture Organization of the United Nations (FAOSTAT, http://faostat3.fao.org/). The term "demand" is defined as the annual amount of NPP required by the sub-Saharan dryland population. Building on earlier work (Abdi et al. 2014), we developed a framework based on FAOSTAT to calculate demand for NPP (Supplementary Fig. 3). We downloaded data from 2000 to 2011 for the components of NPP demand for each country from the food balance sheets provided by FAOSTAT. However, contrary to Abdi et al. (2014), who used the total primary crop production of each country, we used domestic supply quantities to account NPP supply for domestic utilization.

The first component of NPP demand is domestically consumed food $\left(N P P_{\text {food }}\right)$. This category includes twenty-seven types of regionally important primary crops, which represent $95 \%$ of all those that are domestically consumed by most of the countries in the study area (Supplementary Table 2) (FAOSTAT 2015). Additionally, meats sourced from six types of domestic animals (cattle, goats, sheep, pigs, camels, poultry) and two non-meat animal products (eggs and milk) (Supplementary Table 1) were also included.

$$
N P P_{\text {food }}=\overbrace{\left[\left(\sum_{p=1}^{27} P_{p, y}+I_{p, y}-E_{p, y}+S_{p, y}\right) \times D_{p, y} \times C_{p, y}\right]}^{\text {Crops }}+\overbrace{\left[\left(\sum_{a=1}^{7} M_{a, y}\right) \times K_{a, y} \times 0.45\right]}^{\text {Non-crop }}
$$

where, $P, I$ and $E$ are produced, imported and exported quantities of crop type $p$, in year $y ; S$ is the variation (positive or negative) in the stocks of crop type $p$, in year $y ; D$ and $C$ are the crop- 
specific dry matter and carbon conversion coefficients, respectively; $M$ is the wet carcass weight (i.e. without internal organs) of animal type $a$, in year $y$, and $K$ is the dry matter intake required to produce that weight, in year $y$. We converted crop tonnage to carbon units using the conversion factors provided in Supplementary Tables 1 and 2.

Livestock are assets in sub-Saharan Africa. Pastoralists and agro-pastoralists depend on livestock for nutritional value and economic growth. $N P P_{\text {feed }}$ represents the total amount of animal feed required to sustain the livestock population of the region.

$$
N P P_{\text {feed }}=\left(\sum_{a=1}^{6} T_{a, y}\right) \times R_{a, y} \times 0.45
$$

where, $T$ is the Tropical Livestock Unit (TLU) for livestock type $a$, in year $y ; R$ is the annual dry matter requirement as provided in Supplementary Table 3. A ratio of 0.45 was used to convert dry matter into carbon.

Crop residues $\left(N P P_{\text {residues }}\right)$ refer to the parts of the crop that are left over in a field after harvest. Thus, they are not part of the crop yield (i.e. edible seeds, roots, fruits, leaves, or stalks) and vary according to crop type.

$$
N P P_{\text {residues }}=\sum_{p=1}^{23} H_{p, y} \times 0.45
$$

where, $H$ is the residue factor (proportion of non-yield contributing crop phytomass) of crop type $p$, in year $y$. The residue factors applied in Eq. 7 are detailed in Supplementary Table 4.

In most parts of the sub-Saharan Africa household energy demand is met by woodfuels comprising fuel wood and wood charcoal $\left(N P P_{\text {fuel }}\right)$ extracted from the region's dry woodlands. The demand for woodfuels across sub-Saharan Africa is variable and ranges from $55 \%$ in Senegal (Pires 2003) to over $91 \%$ in Malawi (Zulu 2010), but on average it is approximately $80 \%$ across the study area.

$$
N P P_{\text {fuel }}=\overbrace{\left(\sum W_{N C, y} \times 0.58 \times 0.45\right)}^{\text {Non-coniferous }}+\overbrace{\left(\sum W_{C N, y} \times 0.43 \times 0.45\right)}^{\text {Coniferous }}+\overbrace{\left(\sum W_{C H, y} \times 0.75\right)}^{\text {Charcoal }}
$$

where, $\mathrm{NC}, \mathrm{CN}$ and $\mathrm{CH}$ represent non-coniferous, coniferous and wood charcoal. Dry matter conversion ratios of 0.58 and 0.43 were applied to the non-coniferous and coniferous fuel wood, respectively, and a ratio of 0.45 to convert dry matter into carbon (Supplementary Table 5). Wood charcoal was directly converted to carbon content by applying a ratio of 0.75 (Supplementary Table 5).

Landscape fires, both natural and anthropogenic, play an important role in sub-Saharan dryland ecosystems. One of the anthropogenic applications of burning in sub-Saharan Africa is to expand cropland area (Andela and van der Werf 2014). Consequently, the amount of NPP lost to support human demand for food is taken into account. $N P P_{\text {burned }}$ represents domestic human-driven NPP loss resulting from burning of both forest and savanna resources.

$$
N P P_{\text {burned }}=\sum B_{y} \times 0.45
$$

where, $B$ is the total amount of dry matter burnt in year $y$. The data are presented as dry matter content, therefore a ratio of 0.45 was used to convert dry matter into carbon. 
We did not assume a homogeneous per capita consumption within each country due to variations in diet, lifestyle and wealth between urban and rural populations in sub-Saharan Africa. Rather, we applied ratio factors for urban and rural consumption to national sums of each group of products based on statistics from peer-reviewed literature and national household consumption surveys (Supplementary Table 6).

$$
\begin{gathered}
N P P_{\text {demand_urban }}=\overbrace{N P P_{\text {food }}+N P P_{\text {feed }}+N P P_{\text {residues }}+N P P_{\text {fuel }}+N P P_{\text {burned }}}^{\text {Urban }} \\
N P P_{\text {demand_rural }}=\overbrace{N P P_{\text {food }}+N P P_{\text {feed }}+N P P_{\text {residues }}+N P P_{\text {fuel }}+N P P_{\text {burned }}}^{\text {Rural }} \\
N P P_{\text {demand }}=N P P_{\text {demand_urban }}+N P P_{\text {demand_rural }}
\end{gathered}
$$

We derived per capita NPP consumption by dividing rural and urban consumption values by each country's rural and urban population. Grids of urban and rural consumption were then merged to produce a single map of total per capita consumption. We used gridded population data from the WorldPop project (http://www.worldpop.org.uk/) (Linard et al. 2012), which came in three time slices: 2000, 2005, 2010. We interpolated between these time slices using growth rates from the United Nations Population Division (http://esa.un.org/unpd/wpp/) and added an extra year, 2011, to coincide with the FAOSTAT data. We then used the gridded population data as a spatial surrogate to disaggregate per capita demand to grid cells for each year between 2000 and 2011. The years 2012 and 2013 were not included because domestic supply data on food, feed and fuel from FAOSTAT were limited to 2011 at the time of writing. We distinguished urban and rural areas by masking urban extent on the WorldPop grids based on the "Artificial Areas" category in the European Space Agency's GlobCover 2009 land cover map (https://doi.pangaea.de/10.1594/PANGAEA.787668).

\subsection{Statistical analysis}

We tested the data (NPP supply, NPP demand) for temporal autocorrelation before identifying the presence or absence of trends because significant first order autocorrelation can inflate trend significance, leading to a Type I error. A two-sided Mann-Kendall trend test was then applied to evaluate the significance of monotonic trends in the supply and demand of NPP (Mann 1945). The null hypothesis is that our supply or demand data are independent and randomly ordered; the alternative hypothesis is that the data possess a monotonic trend in one or more years in the time series. To account for non-normal distributions of the supply and demand of NPP, the nonparametric Theil-Sen estimate of slope was used to measure the magnitude of the linear trend (Wilcox 2012). The null hypothesis is rejected if the test statistic is different from zero at the $5 \%$ level. Mean $(\mu)$ trends in supply and demand of NPP were calculated to facilitate comparison between different areas across the continent. To quantify the lagged response of NPP to ENSO forcing, we applied a lagged ordinary least squares regression to monthly NPP and Niño 3.4 index time series. This was done by shifting the time series one month at each lag to a maximum of 12 months over the July - June ENSO lifecycle. For the resultant monthly lags, we combined all significant pixels $(P<0.05)$ using 
absolute maximum value compositing (i.e. the highest absolute value is retained for each pixel location). We then partitioned the final image according to the GlobCover 2009 land cover types. Pearson's product-moment correlation was used to quantify the strength of the linear relationship between cropland NPP and FAOSTAT crop production data between 2000 and 2013.

\section{Results and discussion}

\subsection{Trends of NPP supply and demand}

The linear trends of NPP supply and demand are presented in Fig. 1. NPP supply trends over 2000-2013 are significant in $32 \%$ of the area $\left(4.7\right.$ million $\left.\mathrm{km}^{2}\right)$. However, the trends are concentrated in three distinct areas: the western Sahel $\left(\mu=2 \mathrm{~g} \mathrm{C} \mathrm{m}^{-2} \mathrm{yr}^{-1}, P<0.05\right)$, central Africa $\left(\mu=30 \mathrm{~g} \mathrm{C} \mathrm{m}^{-2} \mathrm{yr}^{-1}, P<0.05\right)$ and parts of Zambia, Malawi and Mozambique $\left(\mu=-25 \mathrm{~g} \mathrm{C} \mathrm{m}^{-2} \mathrm{yr}^{-1}, P<0.05\right)$ (Fig. 1a). By contrast, trends of NPP demand over 20002011 are significant in $48 \%$ of the area and roughly evenly distributed (Fig. 1b). The mean overall trend of NPP demand is $3.5 \mathrm{~g} \mathrm{C} \mathrm{m}^{-2} \mathrm{yr}^{-1}$, though in urban areas it averages approximately $50 \mathrm{~g} \mathrm{C} \mathrm{m}^{-2} \mathrm{yr}^{-1}$. The tradeoffs between NPP supply and demand trends (i.e. change in one quantity relative to another) are locally constrained and linked to the

Fig. 1 Linear trends in NPP supply (2000-2013) and demand (2000-2011). NPP supply (a) and NPP demand (b). Detail showing pixel-level supply and demand trends for different urban and rural areas in sub-Saharan Africa: (1) the agricultural region of Sikasso in southern Mali, (2) the Addis Ababa metropolitan area, and (3) southern Malawi within the vicinity of the city of Blantyre. Since the units of NPP supply are generally denoted as quantity per unit area per unit time, and demand generally represents NPP required by the inhabitants in each pixel, we divided each NPP demand pixel in b by its area to facilitate comparability. Grey areas indicate both statistically insignificant $(P>0.05)$ and areas outside the study region

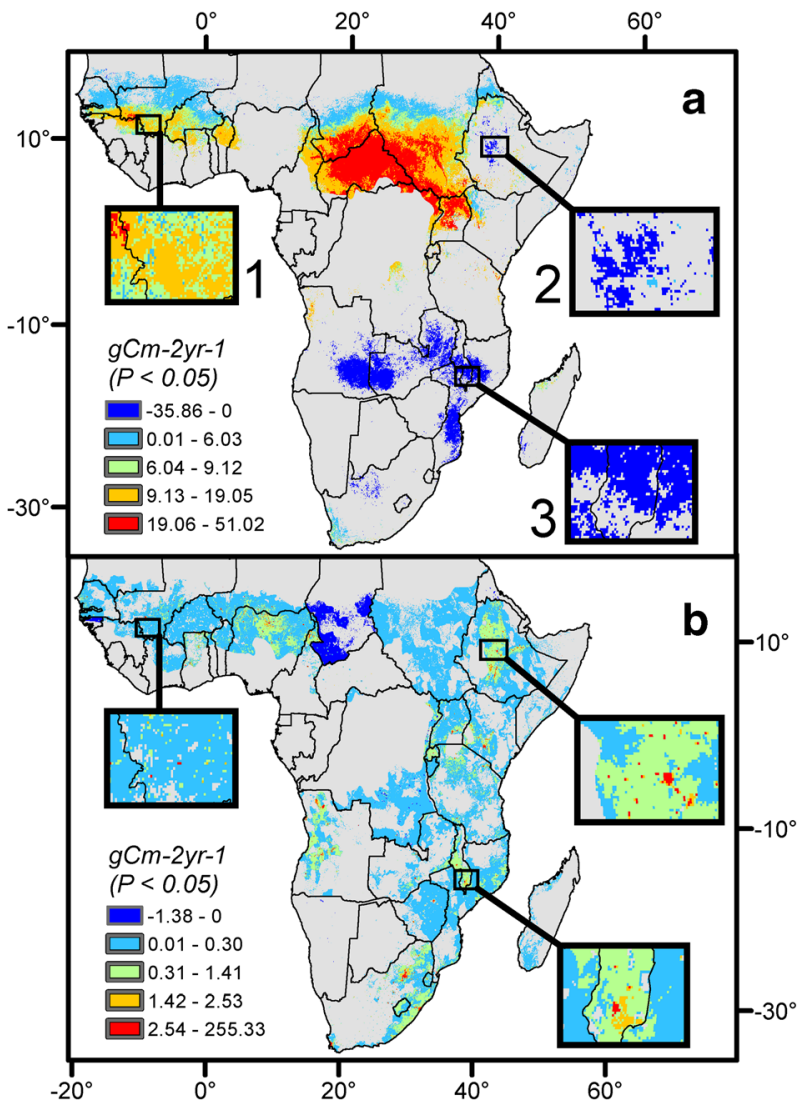


prevailing climate, population growth and net migration. For instance, in the region of Sikasso in southern Mali, the trend of NPP supply averages $10 \mathrm{~g} \mathrm{C} \mathrm{m}^{-2} \mathrm{yr}^{-1}$ (Fig. 1a-1) and that of demand is $1 \mathrm{~g} \mathrm{C} \mathrm{m}^{-2} \mathrm{yr}^{-1}$ (Fig. 1b-1). This region is agriculturally productive and exhibits positive NPP supply anomalies during La Niña (Fig. 2b). The low trend in NPP demand is surprising because the population of Sikasso grew $3.9 \%$ a year between 2000 and 2011 (FAO 2013). This paradox of high land productivity, rapid population growth and low demand for NPP could be a sign that the population is not consuming adequate amounts of food, feed and fuel. Indeed, Eozenou et al. (2013) found that $45 \%$ of the population of Sikasso is classified as "food poor" (i.e. per capita consumption is below the food poverty line) and $19 \%$ are chronically malnourished. Therefore, it is apparent that, despite favorable climatic conditions, agricultural revenues from cotton, the main export crop grown in Sikasso, are insufficient to remove a majority of the region's population out of poverty.

In recent years, major urban areas in sub-Saharan Africa have experienced influxes of economic migrants due to increased investment in infrastructure development (Cheung et al. 2012). Perhaps the best example of this phenomenon is Addis Ababa, Ethiopia. Here, population grew by $40 \%$ between 2000 and 2010 driven by economic migration from other parts of the country (Adugna and Hailemariam 2011; Moller 2012). Consequently, the observed average trend in demand for NPP in the Addis Ababa metropolitan area was $153 \mathrm{~g} \mathrm{C} \mathrm{m}^{-2} \mathrm{yr}^{-1}$ for 2000 2011 (Fig. 1b-2), the highest in sub-Saharan Africa. The observed decrease in NPP supply in the vicinity of Addis Ababa over 2000-2013 (Fig. 1a-2) could be linked to the rapid growth of the city. Itannam and Olsson (2004) found that urbanization and industrialization resulting from Addis Ababa's rapid expansion contributed to land degradation in surrounding agricultural areas. This adversely affects the livelihoods of farmers prompting further economic migration into the city (Abdissa and Degefa 2011). Several La Niña events in the latter half of the analysis period (2007/08, 2008/09, 2010/11) could have further contributed to the observed decrease in NPP supply around Addis Ababa. The impact of ENSO on seasonal rainfall in Ethiopia, and natural hazards associated with strong ENSO, particularly La Niña events, are well documented (Korecha and Sorteberg 2013). La Niña years are correlated with decreased rainfall during the February - May rainy season, potentially extending the November - January dry season through to June (Korecha and Sorteberg 2013; Reda et al. 2015). Furthermore, strong La Niña events induce intense rainfall during the main June - September rainy season, causing floods and subsequent loss in agricultural productivity (Korecha and Barnston 2007; Wolde-Georgis 2002).

In Malawi, approximately $45 \%$ of the population lives in the southern part of the country (van Vuuren et al. 2011), where the vicinity of the country's second-largest city, Blantyre, has experienced an overall decrease in NPP supply $\left(-11 \mathrm{~g} \mathrm{C} \mathrm{m}^{-2} \mathrm{yr}^{-1}\right.$, Fig. 1a-3) over 2000-2013 and an increase of NPP demand $\left(0.80 \mathrm{~g} \mathrm{C} \mathrm{m}^{-2} \mathrm{yr}^{-1}\right.$, Fig. 1b-3). The supply of NPP in this region is highly sensitive to ENSO events (Fig. 2a, b) with a net negative impact. This means that the negative correlation the region has with El Niño outweighs its positive correlation with La Niña (Supplementary Fig. 4). The strong El Niño of 2015/16 reduced the October 2015 February 2016 rainy season to its lowest level since 1981 (FEWSNET 2016). This severe drought condition caused below average crop production leading to low earnings from agricultural labor and high food prices (FEWSNET 2016).

\subsection{ENSO in relation to NPP supply and DSR}

The standardized anomalies of NPP supply and DSR in El Niño (2002/03, 2004/05, 2006/07, 2009/10), La Niña (1999/00, 2000/01, 2005/06, 2007/08, 2008/09, 2010/11) and neutral 

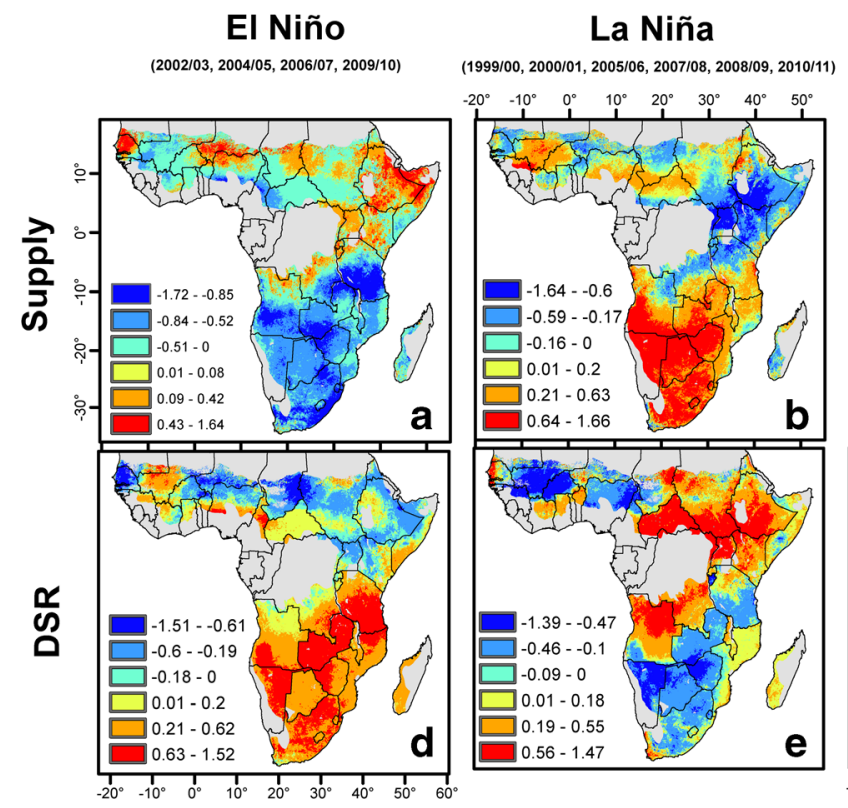

Neutral

(2001/02, 2003/04)
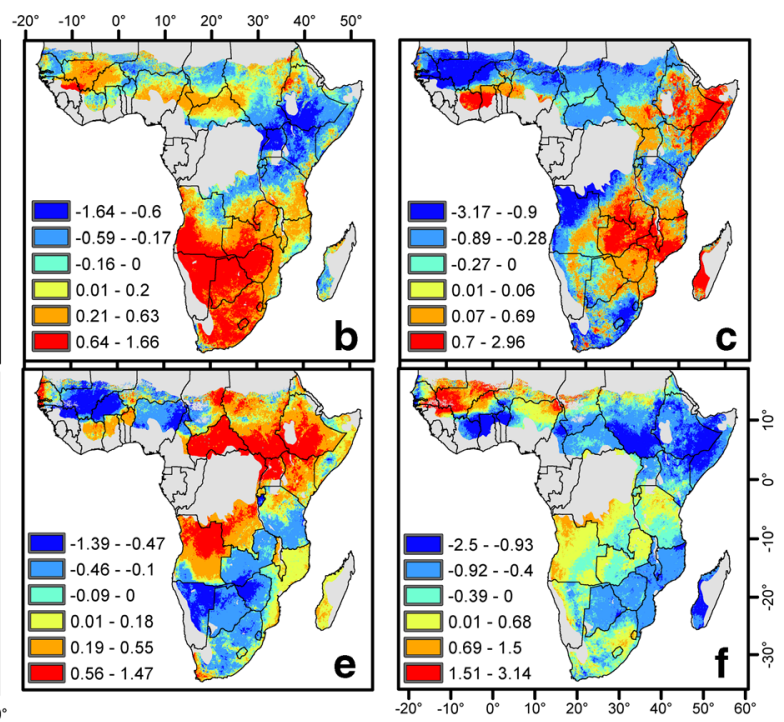

Fig. 2 Standardized anomalies (2000-2011). Standardized anomalies for NPP supply (a, b, c) and demandsupply ratio $(\mathbf{d}, \mathbf{e}, \mathbf{f})$. Means were calculated for El Niño $(\mathbf{a}, \mathbf{d})$, La Niña $(\mathbf{b}, \mathbf{e})$ and neutral years $(\mathbf{c}, \mathbf{f})$. For each panel, the anomaly indicates the number of standard deviations an observation is above or below the mean. The ENSO cycle typically straddles two calendar years, beginning around July, with a peak in December - February, and begins to decay in March - April of the following year. The monthly NPP supply anomalies reflect this cycle and were summed to annual values. Since the FAOSTAT data is provided in calendar years, the DSR data reflects that nomenclature. Accordingly, DSR anomalies shown here represent the latter half of the ENSO cycle, e.g. for the ENSO-neutral years of 2001/02 and 2003/04, the corresponding DSR anomalies are the years 2002 and 2003. Grey areas are outside the study region

(2001/02, 2003/04) phases are presented in Fig. 2. Southern Africa shows the largest contiguous region of negative NPP supply anomalies during El Niño (Fig 2a), and consequently also shows the largest positive DSR anomalies (Fig 2d). Demand for NPP is coupled to population growth and consumption patterns, but it is not linked to, not does it change with, ENSO phases. Consequently, when NPP supply is reduced by El Niño, NPP demand increases relative to it, causing positive DSR anomalies. The opposite effect can be seen during La Niña, when NPP supply anomalies in southern Africa are positive and DSR anomalies are negative. Negative NPP supply anomalies during La Niña are concentrated around equatorial East Africa resulting in positive DSR anomalies (Fig. 2b, e).

The response of NPP supply to ENSO in the Sahel, East and Southern Africa is shown in Fig. 3. The greatest sensitivity occurs in the mainly arid region of Southern Africa (Supplementary Fig. 1). Here, a $+1{ }^{\circ} \mathrm{C}$ shift in the Niño 3.4 index causes a mean change in the NPP supply of $-6.6 \mathrm{~g} \mathrm{C} \mathrm{m}^{-2} \mathrm{yr}^{-1}$. El Niño events in Southern Africa are associated with dry conditions, while La Niña events are associated with wet conditions. Most land cover types in Southern Africa exhibit negative NPP supply values relative to changes in the Niño 3.4 index (Fig. 3). The exceptions, with either the median value or a large number of positive outliers, are the region's forests and woodlands that are adapted to prolonged dry seasons or droughts, and possess physiological mechanisms such as extensive roots allowing efficient deep water access or are drought deciduous (i.e. the trees lose leaves to conserve water) 

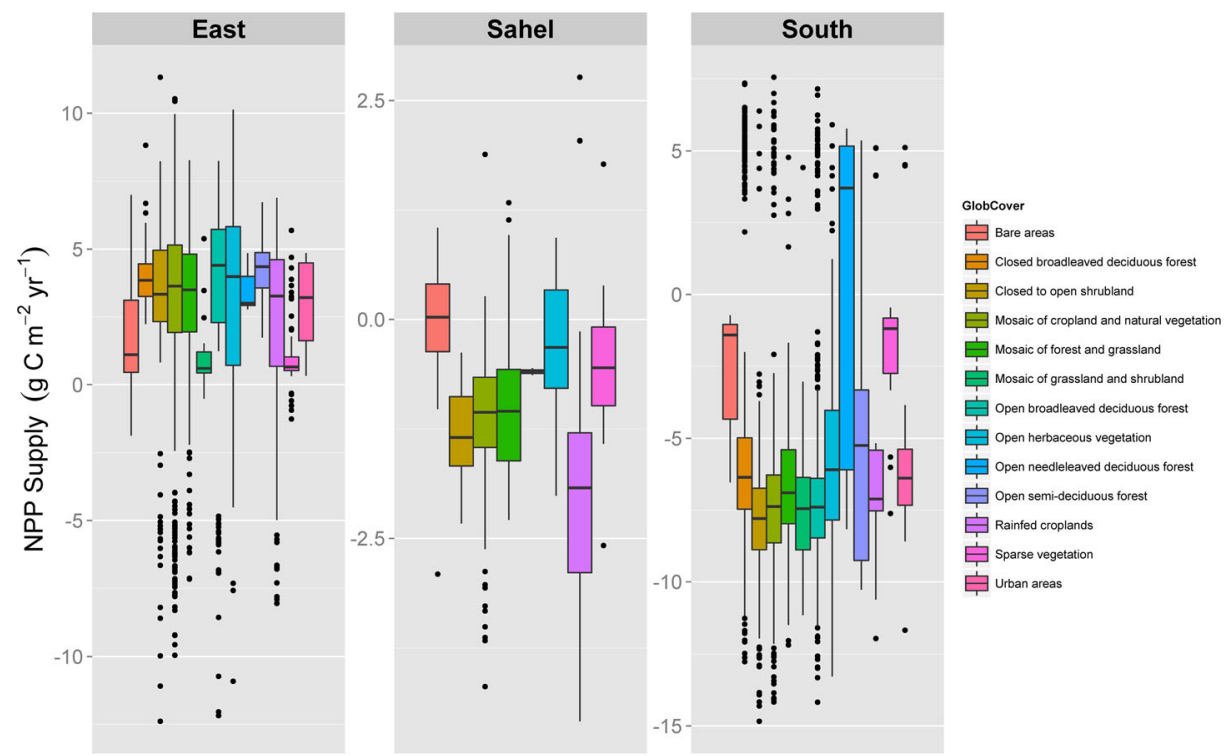

Fig. 3 Relationship between ENSO and NPP supply (2000-2013). Change in NPP supply per GlobCover land cover class relative to $\mathrm{a}+1{ }^{\circ} \mathrm{C}$ change in the Niño 3.4 index anomaly for 2000-2013 $(n=7927)$. Despite the general response of each region to change in the Niño 3.4 anomaly, the presence of a large number of outliers in certain land cover classes could mean that there are underlying physiological adaptations (e.g. water-storing and/ or deep roots systems, drought deciduous, etc.) that surmount the impact of climate

(Nicholson 2011). Despite the fact that there were more La Niña events than El Niño events between 2000 and 2011, the negative impact of El Niño on Southern Africa is strong enough to tip the balance toward the negative (Supplementary Fig. 4). This sensitivity, coupled with a $1.3 \mathrm{~g} \mathrm{C} \mathrm{m}^{-2} \mathrm{yr}^{-1}$ trend in NPP demand, increases demand relative to available supply (Fig. 4a and $b$ ). This is troubling because the difference in NPP supply in Southern Africa between El Niño and La Niña years corresponds to what is required to feed approximately 15 million people for one year (Stige et al. 2006).

\subsection{Demand-supply balance of NPP in food producing regions}

Food production in sub-Saharan drylands is almost entirely dependent on rain-fed agriculture (You et al. 2011). The median response of NPP supply in rain-fed croplands to a $+1^{\circ} \mathrm{C}$ change in the Niño 3.4 region is $-2 \mathrm{~g} \mathrm{C} \mathrm{m}^{-2} \mathrm{yr}^{-1}$ in the Sahel, $3 \mathrm{~g} \mathrm{C} \mathrm{m}^{-2} \mathrm{yr}^{-1}$ in East Africa, and $-7 \mathrm{~g}$ $\mathrm{C} \mathrm{m}^{-2} \mathrm{yr}^{-1}$ in Southern Africa (Fig. 3). Average DSR within rain-fed croplands is high $(\mu=0.9 \pm 0.1$ ), with a large spatial variability (Fig. 5a). In Sahel, East and Southern Africa NPP, demand in croplands, which also includes associated villages and settlements, has been increasing at a rate of $1.35 \%$ per year $(P<0.001)$, while supply has been marginally decreasing at a rate of $0.2 \%$ per year $(P=0.65)$ (Fig. 5b).

These observations reinforce reports of persistent undernourishment in sub-Saharan Africa as approximately $90 \%$ of consumption comes from domestic production (Barrett and Upton 2013). Rain-fed croplands occupy most of the agricultural landscape in sub-Saharan drylands and domestic crop production is strongly linked to cropland NPP (Supplementary Fig. 5). In sub-Saharan drylands, increases in crop production are generally achieved by expanding agricultural land through savanna burning, the spatial patterns of which are determined by the 


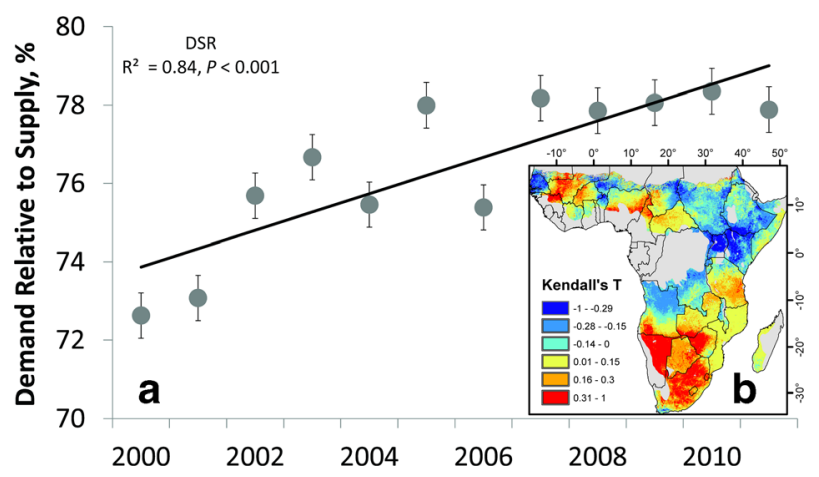

Fig. 4 Trend in DSR and its correlation with ENSO (2000-2011). a Annual trend of the demand-supply ratio expressed as percent across sub-Saharan drylands; (b) Spatial pattern of the correlation between DSR and the Niño-3.4 sea surface temperature index. A positive DSR-Niño 3.4 index correlation signifies decreasing NPP supply relative to demand as Niño 3.4 index values increase (i.e. anomalously warm conditions in the central equatorial Pacific). Negative DSR-Niño 3.4 index correlation means increasing NPP supply relative to demand as Niño 3.4 index values increase. Demand for NPP is always increasing and parallels the rate of population growth. The error bars represent standard error of the mean

ENSO-controlled rainfall regime (Andela and van der Werf 2014). However, despite observed increases in cropland extent in several parts of the continent, yields per unit area for major food crops remain low (Bekunda et al. 2010). Additionally, variability of crop yields in several parts of sub-Saharan Africa can be attributed to ENSO. For example, $64 \%$ of the yield variability of maize in Zimbabwe could be accounted for by ENSO with yield predictions up to a full year before harvest (Cane et al. 1994). Considering these challenges, increasing crop yield means increasing resilience of croplands to the impact of ENSO and other stressors through accurate forecasting and improved land and water management strategies. Water management in particular is vital for crop production and is one of the most important factors required to improve livelihoods in sub-Saharan dryland agro-ecosystems (Sissoko et al. 2011).

a

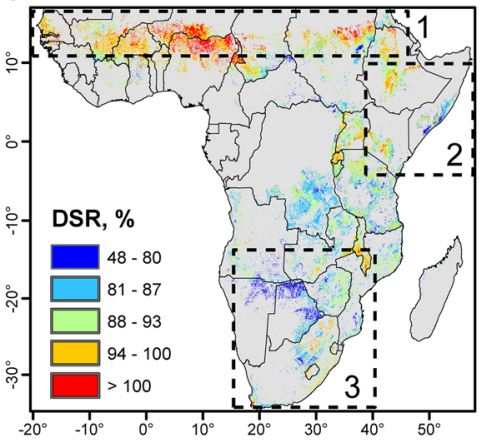

b

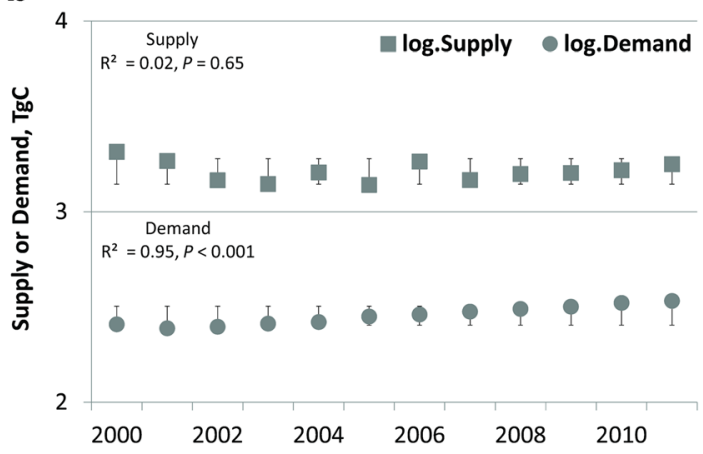

Fig. 5 NPP supply and demand trends in food-producing areas (2000-2011). a Spatial pattern of cropland demand-supply ratio expressed as percent. The dashed boxes denote the high aridity regions of the Sahel (a1), East Africa (a2) and Southern Africa (a3). See Supplementary Fig. 1 for the regional aridity map; (b) Mean annual trend in NPP supply and demand over cropland areas in the Sahel, East and Southern Africa. The error bars represent standard error of the mean 
NPP supply deficiency is exacerbated in sub-Saharan drylands by large-scale, trans-national land acquisitions, whereby investors from countries rich in financial capital purchase or lease land from developing countries for the production of goods (Seaquist et al. 2014). These deals often involve projects that maximize crop yield in purchased land using expensive technologies providing crops, biofuel feedstock and wood charcoal to markets outside the region of production (Seaquist et al. 2014). The 1.3 million $\mathrm{km}^{2}$ of reported deals deplete household income from agricultural production and lead to the displacement of communities (Zetland and Möller-Gulland 2013). Consequently, DSR increases as the consumable supply of NPP is reduced and local resources are depleted to satisfy demand elsewhere (Yengoh and Armah 2015). This external demand for productive land is also an important driver of land degradation and deforestation. Land is acquired to provide maximum return on investment, and thus it is often intensively managed through year-round planting, and excessive use of pesticides and inorganic fertilizers, all factors that contribute to land degradation (Robertson and PinstrupAndersen 2010). The negative effects of deforestation are particularly pronounced in East Africa, where $91 \%$ of the region exhibits an increasing DSR trend $(\mu=0.12 \pm 0.10)$. Rural household energy in East Africa is largely satisfied by wood fuels with around 90 million people living in areas where demand is high and wood harvest unsustainable (Bailis et al. 2015). In countries where there is little or no government regulation the exploitation of local NPP supply to meet external demand is unrestricted. For example, demand for wood charcoal in the Persian Gulf countries drives a $1.4 \%$ annual loss of tree cover in Somalia (Bolognesi et al. 2015).

\subsection{Limitations}

Although DSR provides an indicator of pressures exerted on ecosystem services at large scales, it must be used in combination with other data. This is particularly important at local scales where coarse resolution data cannot capture critical biophysical and socio-ecological processes that occur at higher resolutions. A possible limitation in our approach is the reliance on FAOSTAT data to estimate NPP demand. FAO has traditionally relied on the quality of data provided by national statistical institutions with minimal quality control. However, in recent years the agency has been taking steps through its regional offices to intensify data control and harmonize collection, processing and dissemination with various national partner agencies (FAO 2011). The quantification of human vulnerability to food insecurity is complex and metrics such as those provided by FAOSTAT have been criticized for being poor predictors (Barrett 2010). We addressed this critique by: (1) using household consumption surveys to apply appropriate ratios distinguishing between per capita urban and rural consumption for each component of NPP demand, and (2) spatially constraining these ratios to gridded population data.

\section{Conclusions}

In this paper we focused on the El Niño-Southern Oscillation (ENSO) and its impact on the balance between supply and demand of net primary productivity (NPP) in African drylands. Our analyses demonstrated that fluctuations in the supply of NPP associated with a $+1{ }^{\circ} \mathrm{C}$ change in the Niño 3.4 region average $-2.8 \mathrm{~g} \mathrm{C} \mathrm{m}^{-2} \mathrm{yr}^{-1}$ and population and socioeconomicdriven trend in NPP demand averages $3.5 \mathrm{~g} \mathrm{C} \mathrm{m}^{-2} \mathrm{yr}^{-1}$. The combination of reductions in 
supply and increases in demand lead to a $7.2 \%$ increase in the demand for NPP relative to its supply. Our findings highlight the role played by ENSO and population growth in modulating the balance between supply and demand of NPP in sub-Saharan drylands. Our findings also emphasize the importance of accounting for this balance, which has so far been overlooked in climate impact studies.

Humans rely directly on the supply of NPP through the consumption of crops and use of wood for fuel and construction, and indirectly through animal products. This reliance creates demand that drives many of the ecological changes occurring in sub-Saharan drylands. Evaluating the socio-ecological impact of ENSO and other large-scale ocean-atmosphere teleconnections through isolated disciplinary analysis provides monocular views of a complex system that requires an integrated approach. Moreover, several of the factors that influence the balance between supply and demand, such as population density and consumption patterns, are dependent on scale. Sociological data, such as surveys at the household (or even individual) level, which provide valuable information about fine-scale patterns of human-ecosystem interaction, are seldom integrated with biophysical datasets. Thus, a comprehensive, interdisciplinary approach is required to further assess the factors driving this complex balance in the wake of climate change. Only through interdisciplinary analysis involving enhanced synthesis of both biophysical and socio-ecological data can we make improved assessments of the impacts of climatic variability on human livelihood and wellbeing.

Acknowledgments We thank Dan Metcalfe, Lina Eklund, A.J. (Han) Dolman, and Katharina Waha for their insight and comments during early stages of the manuscript. We also thank the programming assistance provided by the volunteers at the Stack Overflow and Cross Validated online communities. Funding for this project was provided by the Swedish National Space Board (contract no. 100/11 to J.A.). A.M.A. received support from the Royal Physiographic Society in Lund and the Lund University Center for Studies of Carbon Cycle and Climate Interactions (LUCCI). C.C.U. was supported by NSF grant OCE-1203892.

\section{References}

Abdi AM, Seaquist J, Tenenbaum DE, Eklundh L, Ardo J (2014) The supply and demand of net primary production in the Sahel. Environ Res Lett 9:094003

Abdissa F, Degefa T (2011) Urbanization and changing livelihoods: the case of farmers' displacement in the expansion of Addis Ababa. In: Teller C (ed) The demographic transition and development in Africa: the unique case of Ethiopia. Springer Netherlands, Dordrecht, pp. 215-235

Adugna A, Hailemariam A (2011) Rural-urban linkages in ethiopia: insuring rural livelihoods and development of urban centers. In: Teller C (ed) The demographic transition and development in Africa. Springer, Netherlands, pp. 167-186

Ahlström A, Raupach MR, Schurgers G, Smith B, Arneth A, Jung M, Reichstein M, Canadell JG, Friedlingstein P, Jain AK, Kato E, Poulter B, Sitch S, Stocker BD, Viovy N, Wang YP, Wiltshire A, Zaehle S, Zeng N (2015) The dominant role of semi-arid ecosystems in the trend and variability of the land CO2 sink. Science 348:895-899

Andela N, van der Werf GR (2014) Recent trends in African fires driven by cropland expansion and el Nino to La Nina transition. Nat Clim Chang 4:791-795

Bailis R, Drigo R, Ghilardi A, Masera O (2015) The carbon footprint of traditional woodfuels. Nat Clim Chang 5:266-272

Barrett CB (2010) Measuring food insecurity. Science 327:825-828

Barrett CB, Upton JB (2013) Food security and sociopolitical stability in sub-Saharan Africa. Food security and sociopolitical stability. Oxford University Press, New York

Battisti DS, Naylor RL (2009) Historical warnings of future food insecurity with unprecedented seasonal heat. Science 323:240-244

Bekunda M, Sanginga N, Woomer PL (2010) Restoring soil fertility in sub-Sahara Africa. In Donald LS (ed.) Advances in agronomy. Academic Press, pp. 183-236 
Bolognesi M, Vrieling A, Rembold F, Gadain H (2015) Rapid mapping and impact estimation of illegal charcoal production in southern Somalia based on WorldView-1 imagery. Energy Sustain Dev 25:40-49

Cai W, Santoso A, Wang G, Yeh S-W, An S-I, Cobb KM, Collins M, Guilyardi E, Jin F-F, Kug J-S, Lengaigne M, McPhaden MJ, Takahashi K, Timmermann A, Vecchi G, Watanabe M, Wu L (2015) ENSO and greenhouse warming. Nat Clim Chang 5:849-859

Campbell MM, Casterline J, Castillo F, Graves A, Hall TL, May JF, Perlman D, Potts M, Speidel JJ, Walsh J, Wehner MF, Zulu EM (2014) Population and climate change: who will the grand convergence leave behind? The Lancet Global Health 2:e253-e254

Cane MA, Eshel G, Buckland RW (1994) Forecasting Zimbabwean maize yield using eastern equatorial Pacific Sea surface temperature. Nature 370:204-205

Cheung Y-W, de Haan J, Qian X, Yu S (2012) China's outward direct investment in Africa. Rev Int Econ 20:201-220

Eozenou PH-V, Madani D, Swinkels R (2013) Poverty, malnutrition and vulnerability in Mali. World Bank Policy Research Working Paper No. 6561. The World Bank, Washington, DC

FAO (2011) Review of the availability and quality of official data from African commission on agricultural statistics member countries. Food and agriculture Organization of the United Nations, Addis Ababa, Ethiopia

FAO (2013) CountrySTAT Mali. Statistics Division, Food and Agriculture Organization of the United Nations Rome, Italy

FAOSTAT (2015) FAO statistical databases. Food and agriculture Organization of the United Nations, Rome, Italy

Fetzel T, Niedertscheider M, Haberl H, Krausmann F, Erb K-H (2016) Patterns and changes of land use and landuse efficiency in Africa 1980-2005: an analysis based on the human appropriation of net primary production framework. Reg Environ Change 16:1507-1520

FEWSNET (2016) Southern Africa: illustrating the extent and severity of the 2015-16 drought. Famine Early Warning Systems Network/USAID

Giannini A, Biasutti M, Held IM, Sobel AH (2008) A global perspective on African climate. Clim Chang 90: 359-383

Greve P, Orlowsky B, Mueller B, Sheffield J, Reichstein M, Seneviratne SI (2014) Global assessment of trends in wetting and drying over land. Nat Geosci 7:716-721

IPCC (2014) Climate Change 2014: Impacts, Adaptation, and Vulnerability. Part B: Regional Aspects. Contribution of Working Group II to the Fifth Assessment Report of the Intergovernmental Panel on Climate Change. Cambridge, United Kingdom and New York, NY, USA

Itannam F, Olsson M (2004) Land degradation in Addis Ababa due to industrial and urban development. Ethiopian J Dev Res 26:77-100

Knox J, Hess T, Daccache A, Wheeler T (2012) Climate change impacts on crop productivity in Africa and South Asia. Environ Res Lett 7:034032

Korecha D, Barnston AG (2007) Predictability of June-September rainfall in Ethiopia. Mon Weather Rev 135: 628-650

Korecha D, Sorteberg A (2013) Validation of operational seasonal rainfall forecast in Ethiopia. Water Resour Res 49:7681-7697

Linard C, Gilbert M, Snow RW, Noor AM, Tatem AJ (2012) Population distribution, settlement patterns and accessibility across Africa in 2010. PLoS One 7:e31743

Mann HB (1945) Nonparametric tests against trend. Econometrica: Journal of the Econometric Society:245-259

Maxwell D, Fitzpatrick M (2012) The 2011 Somalia famine: context, causes, and complications. Global Food Security 1:5-12

Moller LC (2012) The Ethiopian urban migration study 2008: the characteristics, motives and outcomes to immigrants to Addis Ababa. The World Bank, Washington, DC

Monteith JL (1972) Solar radiation and productivity in tropical ecosystems. J Appl Ecol 9:747-766

Nicholson SE (2011) Dryland climatology. Cambridge University Press

Philippon N, Martiny N, Camberlin P, Hoffman MT, Gond V (2014) Timing and patterns of the ENSO signal in Africa over the last 30 Years: insights from normalized difference vegetation index data. J Clim 27:2509-2532

Pires M (2003) The spatial polarization of woodfuel supply and demand in Senegal. African Geographical Review 22:29-47

Reda DT, Engida AN, Asfaw DH, Hamdi R (2015) Analysis of precipitation based on ensembles of regional climate model simulations and observational databases over Ethiopia for the period 1989-2008. Int J Climatol 35:948-971

Robertson B, Pinstrup-Andersen P (2010) Global land acquisition: neo-colonialism or development opportunity? Food Sec 2:271-283

Running SW (2012) A measurable planetary boundary for the biosphere. Science 337:1458-1459 
Seaquist JW, Johansson EL, Nicholas KA (2014) Architecture of the global land acquisition system: applying the tools of network science to identify key vulnerabilities. Environ Res Lett 9:114006

Sissoko K, van Keulen H, Verhagen J, Tekken V, Battaglini A (2011) Agriculture, livelihoods and climate change in the west African Sahel. Reg Environ Chang 11:119-125

Stige LC, Stave J, Chan K-S, Ciannelli L, Pettorelli N, Glantz M, Herren HR, Stenseth NC (2006) The effect of climate variation on agro-pastoral production in Africa. Proc Natl Acad Sci U S A 103:3049-3053

van Vuuren DP, Edmonds J, Kainuma M, Riahi K, Thomson A, Hibbard K, Hurtt GC, Kram T, Krey V, Lamarque J-F, Masui T, Meinshausen M, Nakicenovic N, Smith SJ, Rose SK (2011) The representative concentration pathways: an overview. Clim Chang 109:5-31

Wilcox R (2012) Chapter 10 - robust regression. Introduction to robust estimation and hypothesis testing, Third edn. Academic Press, Boston, pp. 471-532

Wolde-Georgis T (ed) (2002) The impact of cold events on Ethiopia. United Nations University Press, New York, NY

Yengoh G, Armah F (2015) Effects of large-scale acquisition on food insecurity in Sierra Leone. Sustainability 7 : 9505

You L, Ringler C, Wood-Sichra U, Robertson R, Wood S, Zhu T, Nelson G, Guo Z, Sun Y (2011) What is the irrigation potential for Africa? A combined biophysical and socioeconomic approach. Food Policy 36:770-782

Zetland D, Möller-Gulland J (2013) The political economy of land and water grabs. In: Allan JA, Keulertz M, Sojamo S, Warner J (eds) Handbook of land and water grabs in Africa: foreign direct investment and food and water security. Routledge, New York, NY

Zhao M, Running S, Heinsch FA, Nemani R (2011) MODIS-derived terrestrial primary production. In: Ramachandran B, Justice CO, Abrams MJ (eds) Land remote sensing and global environmental change. Springer, New York, pp. 635-660

Zulu LC (2010) The forbidden fuel: charcoal, urban woodfuel demand and supply dynamics, community forest management and woodfuel policy in Malawi. Energ Policy 38:3717-3730 